\title{
Culture, law, risk and governance: contexts of traditional knowledge in climate change adaptation
}

\author{
Terry Williams • Preston Hardison
}

Received: 9 January 2013 / Accepted: 16 July 2013 / Published online: 15 August 2013

(C) The Author(s) 2013. This article is published with open access at Springerlink.com

\begin{abstract}
Traditional knowledge is increasingly recognized as valuable for adaptation to climate change, bringing scientists and indigenous peoples together to collaborate and exchange knowledge. These partnerships can benefit both researchers and indigenous peoples through mutual learning and mutual knowledge generation. Despite these benefits, most descriptions focus on the social contexts of exchange. The implications of the multiple cultural, legal, risk-benefit and governance contexts of knowledge exchange have been less recognized. The failure to consider these contexts of knowledge exchange can result in the promotion of benefits while failing to adequately address adverse consequences. The purpose of this article is to promote awareness of these issues to encourage their wider incorporation into research, policy, measures to implement free, prior and informed consent (FPIC) and the development of equitable adaptation partnerships between indigenous peoples and researchers.
\end{abstract}

\section{Introduction}

Indigenous peoples are increasingly recognized to possess considerable knowledge on issues related to climate change adaptation (Nakashima et al. 2012). Studies have demonstrated the value of indigenous peoples' observations of changes in climate-related weather patterns (Green and Raygorodetsky 2010), ocean phenomena (Fienup-Riordan and Rearden 2010), phenology (Egeru 2012), and fire behavior (Mason et al. 2012). Their knowledge of past ecological patterns can help reconstruct historical baselines (Thornton and Scheer 2012). Traditional ecological knowledge of ecosystem health and species distributions can contribute to culturally appropriate adaptation (Girot et al. 2011). Traditional knowledge embodied in technologies, practices and cultivated species facilitate coping with climate change (Clements et al. 2011). Traditional water-related knowledge, water harvesting and storage have allowed indigenous peoples to survive in arid lands and cope with drought for millennia (Johnston 2012).

This article is part of a Special Issue on "Climate Change and Indigenous Peoples in the United States: Impacts, Experiences, and Actions" edited by Julie Koppel Maldonado, Rajul E. Pandya, and Benedict J. Colombi.

T. Williams $\cdot$ P. Hardison $(\bowtie)$

Tulalip Tribes Natural Resources Office of Treaty Rights, 6406 Marine Dr., Tulalip, WA 98271, USA

e-mail: prestonh@comcast.net 
Research partnerships for using traditional knowledge and Western science for coping with and adapting to climate impacts offer benefits to both researchers and indigenous communities (Nakashima et al. 2012). Researchers benefit by acquiring a better understanding of indigenous values that need to be accommodated in adaptation planning for landscape restoration and management, traditional technologies for adaptation, and local knowledge to complement the scientific knowledge base. Indigenous communities benefit by acquiring a better understanding of climate change and its impacts and technologies for coping with these impacts that may lie outside of their traditions. Combining ways of knowing can lead to new innovations, knowledge and opportunities for adaptation through mutual learning (co-learning) and mutual knowledge generation (co-production) (Berkes 2009; Nakashima et al. 2012). Through mutually beneficial partnerships, indigenous peoples and scientists can cooperatively work to reduce climate change impacts while maintaining communities' cultural values and resources.

Despite these demonstrated benefits, concerns have been raised over potential adverse consequences of knowledge exchanges (WIPO 2012). Co-learning and co-production processes do not guarantee fairness, equal standing or address power asymmetries (Hill et al. 2012). The cultural, legal, risk-benefit and governance contexts in which knowledge exchanges occur have been under-examined. This paper will outline these contexts and suggest ways to address them. Meeting these concerns presents challenges, but these should not pose a long-term impediment to indigenous-researcher partnerships. Addressing them constitutes a significant step in recognizing their rights to resources and decision-making, reducing long-term conflicts and ensuring equitable partnerships based on free, prior and informed consent (FPIC).

\section{Traditional knowledge in the context of climate change}

Traditional knowledge is useful in: defining earlier environmental baselines, identifying impacts that need to be mitigated, providing observational evidence for modelling, providing technologies for adapting, and for identifying culturally appropriate values for protection from direct impacts or from the impacts of adaptation measures themselves.

In one study from the Clyde River, in Nunavut in the Canadian Arctic, scientists spent years collecting weather data (Weatherhead et al. 2010). Inuit hunters had reported significant changes in wind persistence (likelihood that wind conditions 1 day are followed by similar conditions the following day). The hunters used multiple traditional observations (lack of formation of seasonal ice crusts, changes in snow forms used as navigational aids, animal behavior and sea-ice conditions to conclude that the wind was becoming less persistent and predictable. These observations were not supported by the research station, which recorded no significant changes in wind direction or wind persistence in northeast winds (Weatherhead et al. 2010).

One explanation for the discrepancies is that the weather station was in a fixed flat area at the airport, while Inuit hunters ranged long distances in complex topographies. A significant difference was in what was that hourly measurements of mean wind intensity were limited compared to the needs of hunters who were most interested in changes in snow conditions and wind, any shift in which can mean the difference between life and death if the weather signs are misinterpreted (Weatherhead et al. 2010). Ranges of wind direction and associated sea and ice phenomena matter much more to hunters than means.

The discovery of these discrepancies has led to the establishment of more weather stations around the hunting areas which are being correlated to indigenous weather 
observations, as well as other projects to extend indigenous monitoring of sea-ice thickness, extent and other climate-related phenomena. Importantly, it has helped to focus research on data to support their safety and subsistence needs in a changing climate. For other relevant observations, see Nakashima et al. (2012) and Berkes (2009).

\section{Cultural contexts of traditional knowledge}

Although the phrase "traditional knowledge" will be used throughout this paper, the concept illustrates the kinds of problems pervasive in cross-cultural understanding and knowledge exchanges. Traditional knowledge holders themselves may not express their knowledge in this way (Berkes 2009). Traditional knowledge is a noun phrase, turning knowledge into an object. Traditional knowledge holders commonly think of knowledge as a contextualized process connected to dynamic, evolving relationships expressed in the phrase "ways of knowing" (Berkes 2009).

In a widely influential definition, Berkes has characterized traditional ecological knowledge (TEK) as "a cumulative body of knowledge, practice, and belief, evolving by adaptive processes and handed down through generations by cultural transmission, about the relationship of living beings (including humans) with one another and with their environment" (Berkes 2012). This definition frames TEK within a materialistic, evolutionary framework that does not always conform to the beliefs of the knowledge-holders themselves, who may refer their knowledge as living breath, coming directly from the spirit world, ancestors, dreams, or conversations with plants, trees, rocks or other aspects of a living and spiritual nature (Little Bear 2000). Referring to a "cumulative body of knowledge" appeals to Western concepts of trial-and-error learning. While indigenous peoples are concerned deeply with relationships between humans and the natural world, this definition and many discussions focus on material concept of relationships (i.e. species interactions, social-ecological system interactions) and leave the spiritual dimensions out as metaphysical constructs. These so-called constructs are often at the core of indigenous identity and underpin their beliefs and practices, and ignoring them can create significant impediments to equitable partnerships (Burkett 2013).

Some have proposed dichotomous representations of traditional and Western scientific knowledge systems (Berkes 1993). These have limitations, however, as there is a spectrum of both indigenous and scientific ways of knowing with many areas of overlap (Berkes 2009). Both provide ways of knowing about and acting on the world to reliably achieve desired outcomes.

Differences remain in the way indigenous peoples conceive of intangible values and relationships. Scientists commonly aim to produce validated and transportable knowledge objects that are held to be universally true and objective regardless of cultural background. The scientific ethic is generally to make knowledge widely available ${ }^{1}$. This may be contrasted with traditional ways of knowing which are place-based, localized, and may carry prescriptions related to their use (Kipuri 2009). Indigenous peoples often believe their knowledge has spiritual origins and powers, and employ it to communicate with the spirit world to create outcomes in this world (Kipuri 2009).

Traditional knowledge has been described as being shared freely in a commons (Amankwah 2007), or as un-owned by peoples without property concepts (Helfer and Austin 2011). This has been countered by studies that demonstrate traditional ways of

\footnotetext{
${ }^{1}$ For example, the Berlin Declaration on Open Access to Knowledge in the Sciences and Humanities (2003) http:/oa.mpg.de/lang/en-uk/berlin-prozess/berliner-erklarung/
} 
knowing occur in a wide spectrum of beliefs, norms, institutions and ways of owning that includes property concepts (Carpenter et al. 2009). Thom and Bain (2004) describe many ways in which aboriginal individuals and groups in Canada are the holders, custodians or owners of rights, powers, property and responsibilities. They hold proprietary interests in rituals, private professional knowledge, songs, stories, magic words, dances, shamanic knowledge, fishing sites and myriad other aspects of tribal life. Some weather knowledge may be shared widely, but may also be held by weather shamans holding proprietary knowledge and practices and passing these down through families (e.g., Chumash Indians of California, Timbrook 1987).

Traditional knowledge is regulated by customary norms and embedded in a web of relationships defining who may use it, when it may be used, appropriate uses, and the rituals, words or practices that must accompany its use (Thom and Bain 2004). When traditional knowledge is shared, it is often accompanied by stewardship obligations within communities with expectations that outsiders also carry these obligations when knowledge is shared. This creates significant challenges in terms of the foreign contexts to which it is exposed when conveyed outside community boundaries.

\section{Legal contexts of traditional knowledge}

Once traditional knowledge is shared outside of a community, it enters alien social and legal contexts. Natural scientists often emphasize the value of partnerships with indigenous communities in outcomes-oriented terms. Social science researchers commonly use political, social or moral/ethical frameworks. These approaches emphasize the social aspects of knowledge holder-researcher relationships, promoting reciprocity, respect and protocols for them (Hardison and Bannister 2011). Although a significant advance, these approaches have rarely addressed the legal contexts of these exchanges.

Traditional knowledge holders will often evaluate seekers of knowledge to ensure they have the proper attitudes, maturity and responsibility to receive such knowledge (Noble 2009; Thom and Bain 2004). Once the knowledge has been shared with persons outside of the community, they may in turn share it with third parties who have not agreed to respect social conventions and are not bound by law to do so. Without special legal measures to recognize stewardship obligations associated with the knowledge, it becomes subject to foreign norms and laws that generally automatically apply regardless of the intentions of either the communities or the researchers (Riley 2005). Despite good intentions, protocols and best practices, the exchanged knowledge is not governed by customary laws or community aspirations, but by foreign laws such as intellectual property, freedom of expression, public domain and common heritage of mankind.

Countries have begun to put into place laws that protect such transfers of traditional knowledge to third parties. Under the Nagoya Protocol to the Convention on Biological Diversity, seekers of traditional knowledge related to genetic resources must first obtain the prior informed consent (PIC) of indigenous and local communities. The World Intellectual Property Organization (WIPO) is negotiating a potential international treaty to regulate international access to genetic resources, traditional knowledge and folklore (now referred to as traditional cultural expressions). ${ }^{2}$ A number of countries have passed national laws against appropriation and unfair use (McManis and Terán 2011).

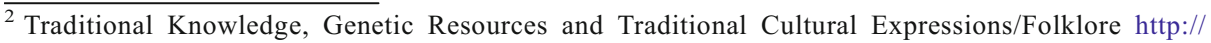
www.wipo.int/tk/en/
} 
However, these measures fall short of fully recognizing and respecting the values, beliefs and customary laws of the traditional knowledge holders themselves. Traditional knowledge is widely treated as secular knowledge and brought into conformation with existing national and international laws. We will not cover these in detail, but will focus on copyright law as a primary example of the conflict between customary law and non-indigenous law, then briefly mention other legal conflicts that require attention. It is important to understand the basics of these laws in order to appreciate the current limitations of social contracts in ensuring respectful partnerships.

\subsection{Intellectual property laws}

\subsubsection{Copyrights}

A copyright is a grant of a temporary monopoly by a government to provide economic incentives to individuals or firms for innovation. Copyright law defines a public domain from which people can freely draw, composed of knowledge that is too old to be protected and once protected knowledge that has exceeded the term of protection. Traditional knowledge is often treated as being in the public domain because it is too old to be protected, it is orally expressed rather than written down ("fixation requirement") ${ }^{3}$, and it cannot be attributed to a specific author. Once published or shared, traditional knowledge immediately starts its journey into the public domain where all of the traditional norms, beliefs or customary laws associated with it are stripped away. It becomes available to anyone with no legal requirement to obtain permission, share in any benefits or observe stewardship obligations for its use.

One aspect of copyright is the "fact/expression" dichotomy. Only the particular expressions in written works are protected, not the underlying ideas which become immediately available for exploitation (Bannister 2004). One example is the Traditional Knowledge World Bank (TKWB) project, a database of traditional knowledge for mitigating desertification and adapting to climate change. ${ }^{4}$ The project intends to support "protection of traditional knowledge rights that can be implemented by persons, communities, disseminators and traditional technique innovators," without indicating how these rights are identified and distinguished from traditional knowledge in the public domain, or how the policy has been implemented in deciding on entries into the database. The project owns the copyright for the descriptions of the traditional adaptation technologies in the database, not the original knowledge holders. The underlying technologies are not protected and may be freely used by anyone.

Copyright law grants fair use exemptions allowing access for research, education, news reporting, parody, commentary and civic deliberation without requiring permission of the copyright holder. These exemptions are fundamental to the functioning of scientific and academic research, but they may not respect indigenous customs. Water rituals, for example, are a common response by indigenous peoples to climate- and weather-related water problems (AIPP 2012). In reviewing publications that recognize relationships between water, heritage, identity and worldviews, one author notes "religious beliefs and customs are often the focus, and examples are often illustrated by photographs of religious festivals or rituals that contribute to conservation of water or demonstrate the intimate spiritual relations people have with water"

\footnotetext{
${ }^{3}$ Copyright generally requires that works be written down, or fixed, in order to receive protection. A few legal systems are beginning to recognize some protection for orally transmitted knowledge.

${ }^{4}$ Traditional Knowledge World Bank, http://www.tkwb.org/

${ }^{5}$ http://www.tkwb.org/web/?page_id $=4$
} 
(Hiwasaki 2012). While such recognition is positive, some cultures believe that publication of photographs of sacred ceremonies interferes with their spiritual power and/or triggers adverse spiritual and physical consequences (e.g. Tsosie 2007).

In the absence of intangible cultural heritage laws, copyright law is automatically applied to any shared traditional knowledge and offers few legal safeguards that allow indigenous peoples to have their traditions respected or to gain benefits from the use of their knowledge.

\subsection{Non-intellectual property laws: freedom of information Act (USA) / freedom of expression / the common heritage of humankind}

Non-intellectual property laws may also serves as impediments to sharing traditional knowledge. Because of a Supreme Court decision in 2001 (Department of Interior v. Klamath Water Users Protective Assn), tribes cannot share sensitive knowledge or information privately with the US on a government-to-government basis, because any exchanges are subject to Freedom of Information Act (FOIA) requests (Doremus and Tarlock 2008).

Disclosed traditional knowledge may also be subjected to claims for use under the right to freedom of expression. Collective customary laws can impose durable restrictions on the use of certain knowledge, practices and symbols, which do not become open to use by others because they have been publicly shared. Current freedom of expression law favors an individual interpretation to justify access to traditional knowledge against customary laws, norms and beliefs (Fletcher 2012; Riley 2007).

The Common Heritage of Mankind asserts that because certain resources are important to humanity as a whole, they should be protected beyond potentially the more narrow concerns of individual sovereign nation states (Curci 2010). Framing intangible cultural heritage as part of the common heritage of humankind can take away governance, ownership and control by indigenous peoples in the name of humanity (Coombe 2009).

Caution should be taken when framing the exchange of traditional knowledge within the social discourses of voluntary guidelines, protocols, partnerships and agreements. Knowledge exchanges occur within powerful and compelling legal frameworks that often conflict with and take precedence over social arrangements. Stewardship obligations generally have no equivalent in national and international legal systems. Social aims for respectful partnerships may be difficult to achieve without changes in legal systems to accommodate indigenous concepts and ways of being.

\section{Risk contexts of traditional knowledge}

A third consideration rests on arguments related to the manner in which sharing decisions are made, which should be based on free, prior and informed consent (FPIC). This concept is contained in the Declaration on the Rights of Indigenous Peoples (UNDRIP) and in decisions of the Convention on Biological Diversity and the Nagoya Protocol as prior informed consent (PIC).

\subsection{Free, Prior and Informed Consent (FPIC)}

FPIC is used in UNDRIP to create procedural safeguards for decision-making by indigenous peoples. FPIC ensures that when they are approached with proposals for access to their lands, resources or traditional knowledge, they are provided with all necessary and appropriate information they deem necessary to make an informed decision (FSC 2012). The 
concept is an extension of informed consent used in medicine, in which doctors have a duty not only inform patients of potential benefits of a procedure or treatment, but also of all relevant risks, and can only proceed with patient consent.

The concepts of FPIC can be understood to mean:

Free The decision must not be coerced or biased. In UNDRIP it emphasizes that decisions should be free from external manipulation, interference and coercion. "Free" has also been used in the Indigenous Peoples Rights Act of 1997 (Republic Act No. 8371) of the Philippines to add the meaning of "determined in accordance with their respective customary laws and practices." The word thus emphasizes freedom to determine the process of decision-making and freedom from coercion.

Prior The term is often described as consent being required prior to access. This may be clear in terms of access to material resources. It is less clear case of traditional knowledge, which may have been disclosed in the past or appear in hybrid forms with other forms of knowledge. UNDRIP holds that permission is required prior to use, even if it has been disclosed, consistent with much customary law.

Consent Consent is usually applied to a legally competent individual, corporate entity or competent authority of a government. In regard to indigenous peoples, decision-making authority may be less clear. There is a wide diversity of social and political organization among indigenous communities. Tribes and First Nations in the US and Canada are organized into governments that have the authority to make decisions, but difficulties may arise because of conflicts of authority between political authorities and the traditional knowledge holders.

Exercising the right to consent creates an obligation on the knowledge holders to establish authoritative decision-making processes. The institutionalization of authoritative processes, while challenging, should decrease conflicts over the long-term.

Indigenous peoples have argued that consent should be applied to both access to undisclosed knowledge or use of already disclosed knowledge. This implies a due diligence requirement to discover potential holders and owners of already disclosed knowledge before putting it into use. It also suggests that researchers need to clarify the pathways by which traditional knowledge is incorporated into research. Clarifying the cultural, legal and ethical dimensions of these pathways and formal mechanisms of consent is a major task of efforts to incorporate traditional knowledge into adaptation decision-making.

Informed This provision holds that indigenous communities must be provided with all necessary relevant information of benefits, costs and risks sufficient to make an informed decision. There are as yet no standards on how to implement this, although there are some emerging attempts (FSC 2012).

To implement this, a traditional knowledge sharing risk assessment should be prepared in collaboration with the traditional knowledge holders, taking into account cultural, legal and governance contexts. Climate adaptation projects often extoll benefits without addressing the potential risks of knowledge sharing, as in two otherwise admirable attempts to survey existing experience, Advance Guard (McLean 2010) and Weathering Uncertainty (Nakashima et al. 2012).

Such considerations may have little effect on decisions to exchange knowledge. Traditional knowledge related to observations of changes in phenology, ice-out dates, coastal currents, fire behavior or hydrological patterns may carry few risks when shared. Other kinds of traditional knowledge carry more risks, either through moral hazards related to cultural 
values or through misuse that can seriously threaten indigenous livelihoods and cultural sustainability. Risks and benefits are linked to specific values held by the knowledge holders, to external legal and social environments and to the characteristics of the resources to which the knowledge is bound. Traditional knowledge is not generally about abstract things, but more focused on relationships and activities that constitute a way of life (Berkes 2012), and these can be harmed by misuse.

Below is an example that illustrates the kind of reasoning that can be applied and indicates where more research is needed to develop FPIC guidance in climate change adaptation (Fig. 1).

\subsection{Risks of sharing climate-relevant traditional knowledge in the coast Salish}

The Coast Salish of the Pacific Northwest live on small territories surrounded by much larger populations with different traditions and values, which increases conflicts over use of resources. Tribes have retained rights to wild resources on off-reservation lands to which they have little control. These uncultivated resources are sensitive to external drivers such as climate change, invasive species, species range shifts, habitat fragmentation and human population growth. Life history characteristics of wild species such as mobility and rarity can exacerbate problems in their governability (characteristics of resources that make them

\section{Risk / Spirituality Matrix}

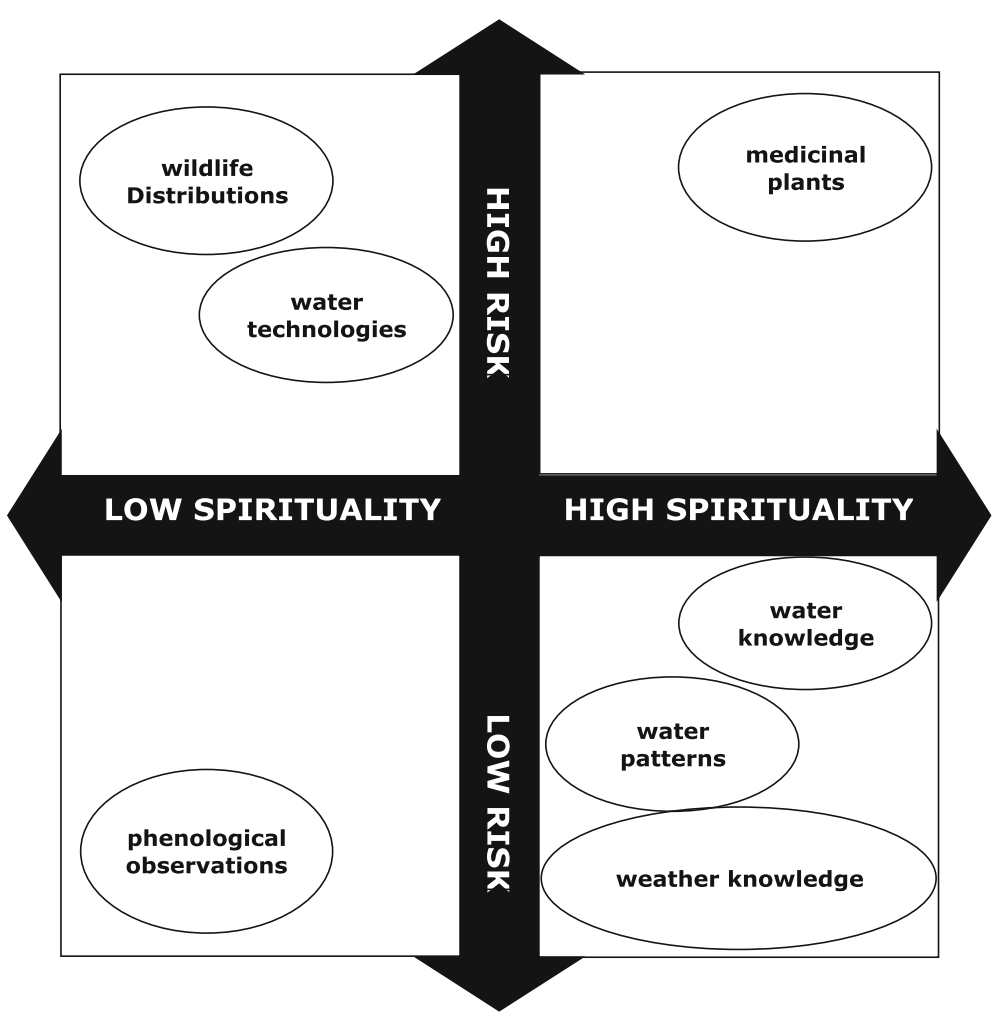

Fig. 1 Matrix illustrating hypothetical trade-offs between types of traditional knowledge with differing levels of spiritual significance and risks related to sharing. Risks include cultural values (moral hazard), material harms (misappropriation and overharvesting) and lack of benefit sharing 
more or less manageable) and governance (characteristics of institutions, norms, laws and policies for their management) relative to cultured species. Coast Salish elders already complain they can no longer access many traditional foods because of overharvesting (Richards and Alexander 2006). Under these conditions, there may be few options for risk spreading through knowledge sharing.

Climate adaptation can be enhanced by traditional knowledge of wildlife movements and concentrations, for which tribal hunters have considerable knowledge (Huntington 2000). Even without cultural sensitivities to sharing, there are risks to publicly revealing the locations of valuable game. These risks can be amplified where tribes have low control over access to game in off-reservation situations.

Disclosing knowledge of medicinal plants useful for addressing climate change impacts on health carries the risks of use against cultural traditions and overharvesting. The bark of the Pacific yew is used for healing wounds by several Pacific Northwest tribes (Moerman 1998), The development of the anti-cancer drug taxol from bark extracts lead to illegal overharvesting in which trees were killed by stripping them entirely, endangering the yew (Laird and Wynberg 2008; Wynberg et al. 2009).

These challenges do not pose an insurmountable barrier to respectful knowledge exchanges. The changes from past practices will likely involve uncertainty and conflicts at first, but will reduce them in the long-run. Exercising the right to FPIC creates a duty to sort out processes for authoritative decision-making. Building respect for traditional knowledge and FPIC through professional training, public education, the development and implementation of guidelines and policies and other measures are necessary to reduce conflict over time (Hardison and Bannister 2011).

Under indigenously-led FPIC, many traditional knowledge exchanges related to climate change are likely to continue where they present few risks and provide benefits to indigenous peoples. The examples emphasize the need for precaution in ensuring their values and rights are protected both against the impacts of climate change and adaptation measures that fail to accommodate their rights and values.

\section{Traditional knowledge governance}

The combined arguments suggest that traditional knowledge exchanges in adaptation partnerships cannot be viewed as unproblematic information exchanges, and potentially carry significant risks as well as benefits and opportunities. Some knowledge useful to adaptation cannot be shared because it is too sacred, risky to disclose or weakly protected from appropriation and misuse. The dilemma often facing indigenous peoples is to either disclose their knowledge and lose control of it, or fail to have their values reflected and protected from climate impacts in adaptation measures. One pathway for resolving this dilemma is through viewing traditional knowledge exchanges through a governance mechanism, as opposed to a voluntary social framework.

Traditional knowledge held by indigenous peoples has significant political or governance dimensions in addition to cultural, legal and risk dimensions. Indigenous peoples are a subject of international law as being a distinct group with a distinct bundle of rights, which they hold as peoples with the right of self-determination (Anaya 2009). While their status as peoples is not universally recognized by all countries, it is affirmed by the United Nations Declaration on the Rights of Indigenous Peoples (2007).

Peoples have the right of self-determination to freely determine their political status and form of governance within their territories (Anaya 2009). Self-determined governments have 
the inherent authority to grant and make trade-offs between the rights of their citizens, but not the rights of the citizens of other sovereigns. Sovereigns work through diplomacy and treaty making to gain cross-recognition for transboundary issues. The number of states that recognize the right to self-determination and self-governance is growing (Anaya 2009).

The Supreme Court has ruled that the tribes' sovereign status is not granted to them by the United States, but an original right reserved by them in the treaties. ${ }^{6}$ This reserved rights doctrine holds that any right not explicitly ceded by treaty is retained as a sovereign right. Consequently, tribal treaties are not legally interpreted as a listing of all rights that are retained, but primarily as a listing of those that are ceded. Any right not explicitly ceded is retained (Pevar 2012). The US has a government-to-government relationship with tribes in which tribes have retained inherent sovereign powers. Traditional knowledge holders are therefore not one stakeholder group among others. The United States Constitution, policy and law recognize them as members of sovereign governments that have retained inherent rights to determine their own laws and constitute their own cultural arrangements and institutions.

Tribal treaties have the fundamental purpose of allowing tribes to freely determine their ways of life in return for the cession of vast amounts of land. Tribes often reserved offreservation rights to fish, hunt, trap and gather because their ancestors understood that their reservations would be insufficient to maintain their ways of life (Goodman 2000). Indigenous peoples have often expressed that their knowledge is inextricably linked to their lands, waters and heritage as inalienable and permanently associated with their identity and territories through ancestral, material and spiritual relationships (Carpenter et al. 2010; Kipuri 2009).

Official US policy affirms that tribes have sovereign rights "to protect tribal cultural heritage and cultural identity expressed in both tangible and intangible forms." 7 Therefore, in the United States it is well-established in Constitutional law and national policy that the tribes have retained unextinguished sovereign jurisdiction over their tangible and intangible cultural heritage. Traditional knowledge is fundamental to the purpose of the treaties and a component of the governance rights reserved in them.

Article 31 of UNDRIP affirms the similar right of indigenous peoples "to maintain, control, protect and develop their cultural heritage, traditional knowledge and traditional cultural expressions, as well as the manifestations of their sciences, technologies and cultures." Although many nations view UNDRIP to be aspirational and not currently legally binding, all signatories have committed themselves to moving towards implementing its principles. The Nagoya Protocol of the Convention on Biological Diversity recognizes the obligation to obtain the prior informed consent of indigenous and local communities prior to accessing and using their knowledge.

In the case of indigenous traditional knowledge, scientists therefore may not be dealing with knowledge and resources held by one stakeholder among many whose rights can be balanced, but with knowledge held collectively by a political entity that has the right of selfdetermination and self-governance. Concepts, instruments and approaches for stakeholder processes are inadequate when addressing issues related to sovereign property, which are dealt with through treaties, bilateral agreements and other government-to-government instruments.

In those cases where traditional knowledge is held by those with governance rights, it is governed by its own rules and laws determined by its proper sovereign, which do not

\footnotetext{
${ }^{6}$ United States v. Winans, 198 U.S. 371 (1905)

${ }^{7}$ Undated letter from David J. Hayes, Deputy Secretary of the Interior to the Tulalip Tribes, received 28 September, 2011 and available from the corresponding author.
} 
necessarily resemble the laws of other sovereigns. While indigenous sovereigns cannot directly impose these rules and laws on citizens of other sovereigns, they can expect that equitable relationships can be worked out for cross-recognition of their issues based on comity guiding peaceful relations among states, respect for their human rights, and federal fiduciary obligations to respect their rights (Smith 2010). These rights are not limited to treaty tribes, but are increasingly recognized as a general right of indigenous peoples in international law, national constitutions and national legislation (Tsosie 2013).

Under conditions of sovereignty, governments may elect to engage in co-management or self-management of their resources and heritage (Goodman 2000; Nie 2008). In this case, co-management refers to a situation in which sovereign powers have equal status in determining an outcome related to shared sovereign resources. One sovereign cannot unilaterally impose their will on another, and equitable outcomes must be found in mutually agreed terms. Many cases of issues related to adaptation to climate change may involve both traditional knowledge and its associated biocultural heritage. In the classic model, federal scientists might request access to traditional knowledge to assess its validity and applicability to managing resources on the federal landscape. In a comanagement and self-management model, indigenous peoples are recognized to have governance rights over their biocultural heritage, including tangible forms (resources) and intangible forms (traditional knowledge), both on their territories and in specified external areas.

Useful and unproblematic knowledge exchanges can occur without involving traditional knowledge. Where traditional knowledge is needed, solving management problems may not require its transfer, allowing indigenous peoples to apply their knowledge by themselves to their own biocultural heritage using negotiated outcomes that are mutually agreeable to the sovereigns (Davidson-Hunt et al. 2012). This performance-oriented approach allows the knowledge to be retained by the knowledge holders while upholding standards for public accountability in the management of resources.

Many traditional knowledge studies have framed indigenous peoples as stakeholders and have not treated traditional knowledge as a governed, sovereign property. Governance rights over traditional knowledge are not separable from governance rights over the biocultural heritage to which they are associated. This is not to argue that traditional knowledge exchanges should not occur, but their rights of governance should be taken seriously, respected and accommodated in resolving issues. The guiding principle is that exchanges should be based on free, prior and informed consent and mutually agreed terms based on equal standing.

\section{Respect for indigenous governance in a climate change context}

An example of using traditional knowledge in a respectful manner for climate change adaptation comes from the Waswanipi Cree in Northern Quebec through the Ndhoho Itschee Process (Trosper et al. 2012). They are interested in documenting their traditional forest knowledge in order to enter into respectful stewardship agreements to promote climate change adaptation and appropriate forest management on traditional lands not under their direct control. They do not believe they can convey their complex knowledge and values to others for management on their behalf, but want their stewardship role acknowledged. Communities are producing detailed community "family maps" which detail past, present and future desired land use. These maps are not shared outside the community. The maps are used to prepare a map of conservation values, which are shared with the government and 
industry for use in collaborative planning processes. In this way, they retain and manage sensitive cultural knowledge internally, while making available proxy values useful for climate change adaptation and resource scenario building.

A review of 21 case studies of natural resources management in Australia resulted in a classification of resource management initiatives as indigenous governed collaborations, indigenous-driven co-governance, agency-driven co-governance and agency governance (Hill et al. 2012). They concluded that "indigenous-driven co-governance provides better prospects for integration of IEK and western science for sustainability of social-ecological systems" than agency-driven co-governance and agency governance. They stress the importance of processes that support indigenous governance and do not vest power in government agencies but instead distribute decision making in "wider networks of families and communities" (Hill et al. 2012).

Berkes suggests there are limits to the extent to which science and traditional knowledge can be combined (Berkes 2009), concluding "the two kinds of knowledge should not be blended or synthesised; both should retain its own integrity" as they have their own epitemologies based on different worldviews. "Not taking knowledge out of its cultural context is one of the biggest challenges of indigenous knowledge research" (Berkes 2009).

\section{Conclusion}

This review raises issues beyond the narrow context of the exchange of information useful for solving climate-related problems. The exchange of traditional knowledge involves cultural values, multiple legal jurisdictions, risks to cultural sustainability and survival and rights to self-governance. Indigenous peoples are engaging in adaptation projects and knowledge exchanges, and these are leading many documented benefits. Despite these documented benefits, it must be kept in mind they are being invited to mobilize traditional knowledge, often deeply spiritual and core to their identity, to solve large-scale problems they cannot avoid and that are not of their making.

Traditional knowledge and associated biocultural heritage are often already threatened by drivers of global climate change such as population growth, urban sprawl, excessive consumption and land conversion. The consequences of disclosing valuable knowledge can add to these pressures. Indigenous peoples may be wary of sharing because of a history of exploitation, a lack of recognition and respect for their values and rights, a lack of safeguards for the control and proper use of their knowledge and associated biocultural heritage and by a lack of perceived long-term benefits to themselves for sharing. Partnership arrangements without proper safeguards may be encourage them to disclose relatively unprotected knowledge associated with relatively unprotected resources. Knowledge sharing and learning from one another will be critical for finding just and lasting solutions to the climate crisis. As indigenous peoples are some of those least responsible and most threatened by climate impacts, it is the highest duty of those seeking access to their knowledge and resources to ensure they are not further harmed and that their rights in cultural values are fully respected.

These arguments have focused on accommodating indigenous peoples and protection of traditional knowledge. While indigenous peoples wish to keep some of their gifts to themselves, it is clear many also wish to share some of them in the spirit of mutualism and reciprocal accommodation. The earth system is in decline and the indigenous concept of stewardship obligations is a good starting point for healing. 
Open Access This article is distributed under the terms of the Creative Commons Attribution License which permits any use, distribution, and reproduction in any medium, provided the original author(s) and the source are credited.

\section{References}

AIPP (2012) Indigenous peoples and climate change adaptation in Asia. Asia Indigenous Peoples Pact (AIPP), Thailand, $24 \mathrm{pp}$

Amankwah HA (2007) Traditional values and modern challenges in property law. J South Pac Law 11:18-38 Anaya SJ (2009) International human rights and indigenous peoples. Wolters Kluwer Law \& Business, New York

Bannister K (2004) Indigenous knowledge and traditional plant resources of the Secwepemc first nation. In: Riley M (ed) Indigenous intellectual property rights: Legal obstacles and innovative solutions. AltaMira Press, Walnut Creek, pp 279-308

Berkes F (1993) Traditional ecological knowledge in perspective. In: Inglis JT (ed) Traditional ecological knowledge; concepts and cases. International Program on Traditional Ecological Knowledge, Ottawa, pp 1-10

Berkes F (2009) Indigenous ways of knowing and the study of environmental change. J R Soc N Z 39:151-156

Berkes F (2012) Sacred ecology. Routledge, London

Burkett M (2013) Indigenous environmental knowledge and climate change adaptation. In: Abate RS, Kronk EA (eds) Climate change and indigenous peoples: The search for legal remedies. Edward Elgar, Cheltenham, pp 96-118

Carpenter KA, Katyal SK, Riley AR (2009) In defense of property. Yale Law J 118:1022-1125

Carpenter KA, Katyal SK, Riley AR (2010) Clarifying cultural property. Int J Cult Prop 17:581-598

Clements R, Haggar J, Quezada A, Torres J (2011) Technologies for climate change adaptation-agriculture sector. UNEP Risø Centre, Roskilde

Coombe RJ (2009) The expanding purview of cultural properties and their politics. Annu Rev Law Soc Scie 5:393-412

Curci J (2010) The protection of biodiversity and traditional knowledge in international Law of intellectual property. Cambridge University Press, Cambridge

Davidson-Hunt IJ, Turner KL, Mead ATP, Cabrera-Lopez J, Bolton R, Idrobo CJ, Miretski I, Morrison A, Robson JP (2012) Biocultural design: a new conceptual framework for sustainable development in rural indigenous and local communities. Sapiens 5:33-45

Doremus HD, Tarlock AD (2008) Water War in the Klamath basin: Macho Law, combat biology, and dirty politics. Island Press, Washington, DC

Egeru A (2012) Role of indigenous knowledge in climate change adaptation: a case study of the teso Subregion, eastern Uganda. Indian J Tradit Knowl 11:217-224

Fienup-Riordan A, Rearden A (2010) The ice is always changing: Yup'ik understandings of sea ice, past and present. In: Krupnik I, Aporta C, Gearheard S, Laidler GJ, Holm LK (eds) SIKU: knowing Our Ice: Documenting Inuit Sea Ice knowledge and Use. Springer, Berlin, pp 303-328

Fletcher MLM (2012) Resisting congress: Free speech and tribal law. In: Carpenter KA, Fletcher MLM, Riley AR (eds) The Indian civil rights Act at forty. UCLA American Indian Studies Center, Los Angeles, pp $133-158$

FSC (2012) FSC Guidelines for the Implementation of the Right to Free, Prior and Informed Consent (FPIC). Version 1. Forest Stewardship Council (FSC), Bonn

Girot P, Ehrhart C, Oglethorpe JwR, Hannah, Rossing T, Gambarelli G, Jeans H, Barrow E, Martin S, Ikkala N, Phillips J (2011) Integrating Community and Ecosystem-Based Approaches in Climate Change Adaptation Responses. Ecosystems and Livelihoods Adaptation Network (ELAN), p. 19pp

Goodman EC (2000) Protecting habitat for off-reservation tribal hunting and fishing rights: tribal comanagement as a reserved right. Environl Law 30:279-361

Green D, Raygorodetsky G (2010) Indigenous knowledge of a changing climate. Clim Chang 100:239-242

Hardison PD, Bannister K (2011) Ethics in ethnobiology: History, international law and policy, and contemporary issues. In: Anderson EN, Pearsall D, Hunn E, Turner N (eds) Ethnobiology. John Wiley \& Sons, Hoboken New Jersey, pp 27-49

Helfer LR, Austin GW (2011) Human rights and intellectual property: Mapping the global interface. Cambridge University Press, New York

Hill R, Grant C, George M, Robinson CJ, Jackson S, Abel N (2012) Typology of indigenous engagement in Australian environmental management: Implications for knowledge integration and socialecological system sustainability. Ecol Soc 17(1):23 
Hiwasaki L (2012) 'Water for Life'.. water for whose life? water, cultural diversity and sustainable development in the united nations. In: Johnston BR (ed) Water, cultural diversity, and global environmental change: Emerging trends, sustainable futures? Springer, Berlin, pp 509-531

Huntington HP (2000) Using traditional ecological knowledge in science: methods and applications. Ecol Appl 10(5):1270-1274

Johnston BR (2012) Water, cultural diversity, and global environmental change: Emerging trends, sustainable futures? United Nations Educational, Scientific and Cultural Organization (UNESCO), Paris

Kipuri N (2009) Culture. in UNDSP (ed.) State of the world's indigenous peoples. united nations division for social policy and development-Secretariat of the Permanent Forum on Indigenous Issues, New York, New York, pp. 52-81

Laird S, Wynberg R (2008) Access and benefit-sharing in practice: Trends in Partnerships Across Sectors. Secretariat of the Convention on Biological Diversity (SCBD), Montreal, Quebec

Little Bear L (2000) Jagged worldviews colliding. In: Battiste M (ed) Reclaiming indigenous voice and vision. University of British Columbia Press, Vancouver, pp 77-85

Mason L, White G, Gea M (2012) Listening and learning from traditional knowledge and Western Science: a dialogue on contemporary challenges of forest health and wildfire. J For 110:187-193

McLean KG (2010) Advance guard: Climate change impacts, adaptation. Mitigation and Indigenous Peoples. United Nations University-Traditional Knowledge Initiative, Darwin

McManis C, Terán Y (2011) Trends and scenarios in the legal protection of traditional knowledge. In: Wong T, Dutfield G (eds) Intellectual property and human development: current trends and future scenarios. Cambridge University Press, New York, pp 139-166

Moerman DE (1998) Native American ethnobotany. Timber Press, Portland

Nakashima DJ, Galloway McLean K, Thulstrup HD, Ramos Castillo A, Rubis JT (2012) Weathering uncertainty: Traditional knowledge for climate change assessment and adaptation. United Nations Educational, Scientific and Cultural Organization (UNESCO), Paris

Nie M (2008) The Use of co-management and protected land-use designations to protect tribal cultural resources and reserved treaty rights on Federal Lands. Nat Res J 48:585-647

Noble B (2009) Owning as belonging/owning as property: The crisis of power and respect in first nations heritage transactions with Canada. In: Bell C, Napoleon V (eds) First nations cultural heritage and Law: Case studies, voices, and perspectives. UBC Press, Vancouver, pp 465-488

Pevar S (2012) The rights of Indians and tribes. Oxford University Press, New York

Richards RT, Alexander SJ (2006) A social history of wild huckleberry harvesting in the pacific northwest. US department of agriculture forest. Service-Pacific Northwest Research Station, Portland

Riley AR (2005) "Straight stealing": towards an indigenous system of cultural property protection. Wash Law Rev 80:69-165

Riley AR (2007) Good (native) governance. Columbia Law Rev 107:1049-1125

Smith C (2010) Full faith and credit in cross-jurisdictional recognition of tribal court decisions revisited. Calif Law Rev 98:1393-1436

Thom B, Bain D (2004) Aboriginal intangible property in Canada: An ethnographic review. Industry Canada Marketplace Framework Policy Branch, Ottawa

Thornton TF, Scheer AM (2012) Collaborative engagement of local and traditional knowledge and science in marine environments: a review. Ecol Soc 17:8

Timbrook J (1987) Virtuous herbs: plants in Chumash medicine. J Ethnobiol 7:171-180

Trosper RL, Clark F, Gerez-Fernandez P, Lake F, McGregor D, Peters CM, Purata S, Ryan T, Thomson A, Watson AE, Wyatt S (2012) North America. In: Parrotta JA, Trosper RL (eds) Traditional forest-related knowledge: Sustaining communities, ecosystems, and biocultural diversity. Springer, Dordrecht, pp 15-201

Tsosie R (2007) Cultural challenges to biotechnology: native American genetic resources and the concept of cultural harm. J Law, Med Ethics 36:396-411

Tsosie R (2013) Climate change and indigenous peoples: Comparative models of sovereignty. In: Abate RS, Kronk EA (eds) Climate change and indigenous peoples: The search for legal remedies. Edward Elgar, Cheltenham, pp 79-95

Weatherhead E, Gearheard S, Barry RG (2010) Changes in weather persistence: insight from Inuit knowledge. Glob Env Change 20:523-528

WIPO (2012) Intellectual property and genetic resources, traditional knowledge and traditional cultural expressions. WIPO, Geneva

Wynberg, R, Schroeder, D, Chennells, R (2009) Indigenous Peoples, Consent and Benefit Sharing: Lessons from the San-Hoodia Case. Springer, Berlin 